This is the accepted version of the following article:

Vid Simoniti, 'Virginia Woolf, Literary Style and Aesthetic Education', Journal of Aesthetic Education

Vol. 50, No. 1 (Spring 2016), pp. 62-79.

DOI: 10.5406/jaesteduc.50.1.0062

The final version available here:

http://www.jstor.org/stable/10.5406/jaesteduc.50.1.0062

Please cite the final version only.

\title{
Virginia Woolf, Literary Style and Aesthetic Education
}

\author{
Vid Simoniti
}

\section{Biographical note}

Vid Simoniti is working on a doctorate in history and philosophy of art at the Ruskin School of Art at the University of Oxford. He holds a B.Phil. in Philosophy from the same university and was formerly the editor of the Postgraduate Journal of Aesthetics.

\section{Introduction}

Works of literature represent stories, characters and events: these are the contents of a work. Often, the contents of literary works are fictional, however, it is just as characteristic of works of literature that these contents are narrated in a distinct style of writing, in an author's distinct literary 'voice'. In this paper, I consider whether works of literature might represent something over and above their fictional contents in virtue of their style alone, and what consequences this might have for our thinking about aesthetic education. Both of these concerns - with what works of art represent and what kind of knowledge they make available to us - have been central to recent analytic philosophy of art, however, while I will pay due attention to these debates, my main route into the question will not be through philosophy but by means of considering Virginia Woolf's writing on the modernist break with earlier stylistic conventions. Introducing the question in the context of Woolf's writings will take up section 1 of this paper. In section 2 , I will formulate a theory 
of stylistic representation inspired by some of Woolf's essays. According to this view, a literary style represents a cognitive disposition: a distinct, dispositionally defined cognitive habit of making sense of the world. In section 3 I will compare this theory with some possible contenders drawn from analytic philosophy of art, and in section 4 I outline how such a theory might help us evaluate innovations in literary style in terms of the kind of aesthetic education they make available to the reader. In this way, I suggest we may read Woolf's remarks on the modernist experiment in literary style as preliminary work for a theory of how innovations in style make new kinds of understanding available to the reader.

\section{The Edwardians and the Georgians: Virginia Woolf and Literary Style}

Let me begin by considering a short excerpt from Virginia Woolf's Mrs Dalloway. This is the third paragraph into the novel, after we learn that Mrs. Dalloway decided to go buy the flowers herself.

What a lark! What a plunge! For so it had always seemed to her, when, with a little squeak of the hinges, which she could hear now, she had burst open the French windows and plunged at Bourton into the open air. How fresh, how calm, stiller than this of course, the air was in the early morning; like the flap of a wave; the kiss of a wave; chill and sharp and yet (for a girl of eighteen as she then was) solemn, feeling as she did, standing there at the open window, that something awful was about to happen; looking at the flowers, at the trees with the smoke winding off them and the rooks rising, falling; standing and looking until Peter Walsh said, "Musing among the vegetables?"- was that it?-“I prefer men to cauliflowers"-was that it? 
The content of the passage is not immediately clear, but the reader soon realises it is about a memory that Clarissa Dalloway had as she left her home. She remembered a conversation she had when she was a girl of eighteen, back in the countryside, at Bourton. What I want to draw attention too, however, is not the content but the literary style of the passage. This style, it seems, communicates something in addition to the content; indeed, the novel as a whole, written in Woolf's pioneering stream of consciousness style, seems to communicate something about the nature of thought processes. Our thoughts appear less fixed, less deliberate and less predictable as we might have hitherto considered them to be. But what kind of representation is this? How can a choice of style represent something as general as the psychology of human thoughts?

This is the question I propose to address in this paper: is there such a thing as representation in virtue of literary style, and what kind of representation is it? We should say, first of all, a bit more about what style is. We may begin such a description by drawing a contrast between style and content. While literary content has to do with what is fictionally the case in the work, style has to do with how that content is narrated. More precisely, we might describe style as the property of the literary text, which is recognizable across a given work through a consistent use of motifs, themes, techniques, imagery, word choice, point of view, emphasis, grammar, punctuation, and other literary devices. It would pay to note that this notion of style might not be completely separable from content. For example, the imagery and motifs of magical realism might necessitate that certain kinds of extraordinary things tend to be fictionally the case in works written in that style. Nevertheless, it seems possible to at least in principle draw a distinction between style and content: the same content can be depicted in a variety of styles. 
In Anglophone aesthetics, the idea that works of art represent something beyond their fictional contents, and that they represent that something in virtue of their style, has been around since at least Arthur Danto's The Transfiguration of the Commonplace. Danto suggested, famously, that unlike mere representations works of art 'use the means of representation in a way that is not exhaustively specified when one has exhaustively specified what is being represented.'2 This constitutes the artistic style of the work, and is a way for an artist to express some meaning in addition to what is being represented. ${ }^{3}$ However, this suggestion has since then mostly been dropped from the philosophical agenda. Sporadically, aestheticians have addressed related questions: what is the concept of style $?^{4}$ is style part of the definition of art, and do only artworks have styles? ${ }^{5}$ which styles of pictorial depiction are realistic? ${ }^{6}$ However, there has been little debate about the puzzle expressed by Danto's distinction between artworks and mere representations. Artworks can communicate something over and above their fictional contents, and they seem to do so in virtue of their style. How to characterize this kind of representation is the question I will tackle here, though I will limit my debate to literary style rather than the visual arts discussed by Danto. I will start not by enumerating available positions within analytic philosophy, but by reconstructing what I believe to be an interesting position on the subject found elsewhere, in the essayistic writings of Virginia Woolf herself. I will return to analytic philosophy of art in section 3, when I will consider Woolf's views side by side with some more recent philosophical suggestions as to the nature of literary style.

In several of her essays written in the early $1920 \mathrm{~s},{ }^{7}$ Virginia Woolf tries to pinpoint what it is that distinguishes her generation of British writers from their predecessors. The term 'modernism' is not yet available to Woolf, who instead 
speaks of two camps: the Edwardians, among whom she counts Arnold Bennett, John Galsworthy and H.G. Wells; and the Georgians, among whom she counts E.M. Forster, D.H. Lawrence, Lytton Strachey, James Joyce, T.S. Eliot, and, we may presume, herself. ${ }^{8}$ Woolf's analysis of the difference between the groups comes across particularly well in the essay 'Mr. Bennett and Mrs. Brown.' Here, in a characteristic mixture of critical reflection and fictional narrative, she describes a seemingly insignificant encounter on the train, a short exchange between an elderly woman and a middle-aged man. Woolf then imagines a poetic contest between the Edwardians and the Georgians; the task is to describe the old lady, who is given the every(wo)man name Mrs. Brown. This seemingly most elementary of a novelist's tasks, to recount a simple everyday encounter, becomes the stomping ground on which the two movements will battle out what is artistically at stake.

Two themes in Woolf's essay are of particular relevance to our question. The first is that what the two generations represent differently is something that Woolf variably refers to as 'human character' or 'human nature.' This is what Mrs. Brown stands for: from one train stop to the next, 'Mrs. Brown is eternal, Mrs. Brown is human nature, [...], it is the novelists who get in and out." ${ }^{, 9}$ The task for the contest is then not to describe this or that particular person, but something more general and of deeper significance. The second important theme is that the distinction between the two camps is not a difference in the represented fictional contents, but a difference in style. It is not that Edwardians and Georgians explore radically different subjects: it is not that the former write about one social class, and the latter about another; or that the former write about fantastical voyages, and the latter about everyday occurrences. The difference is rather in what Woolf calls 'a set of literary conventions' or 'tools' - what we might term 'style. ${ }^{10}$ In short, we have 
here Woolf formulating a question that is very similar to our own: how does a difference in literary style allow an author to represent something of considerable generality, in this case something about human nature?

Before we give more attention to the question itself, though, let us briefly consider the differences between the Edwardian and Georgian styles. The Edwardian writers, according to Woolf, concentrate in their style of writing chiefly on the creation of contrasting, strongly delineated fictional personas. In part, this is achieved with attention to the odd and the particular: 'an English writer,' she writes presumably with the Edwardians in mind, 'would make the old lady into a 'character'; he would bring out her oddities and mannerisms; her buttons and wrinkles; her ribbons and warts; her personality would dominate the book. ${ }^{11}$ The creation of such a believable character is, as Arnold Bennett writes in a passage quoted by Woolf, the foremost task of the novelist. ${ }^{12}$ In doing so, Edwardians also rely on a great deal of description and realistic detail. Woolf imagines Mr. Bennett's instructions to a young novelist: 'Begin by saying that her father kept a shop in Harrogate. Ascertain the rent. Ascertain the wages of shop assistants in the year 1878. Discover what her mother died of. Describe cancer. Describe calico.

Describe.... ${ }^{13}$ The Edwardian style is highly descriptive, and focuses on social facts, fixed psychological characteristics and material circumstances of people. Elsewhere Woolf calls this kind of style 'materialism. ${ }^{\text {'14 }}$

The Georgian, modernist style breaks with both the creation of personnas and with the detailed description of material facts (both of which, one can notice, are absent from the passage quoted from Mrs. Dalloway). Woolf is rather more reticent in describing the Georgian style, but comes closest to articulating what it is like when she writes about what the Edwardians have overlooked. This is what is absent 
from materialism: 'You have overheard scraps of talk that filled you with amazement. You have gone to bed at night bewildered by the complexity of your feelings. In one day thousands of ideas have coursed through your brains; thousands of emotions have met, collided, and disappeared in astonishing disorder. ${ }^{15}$ What replaces the Edwardian pedantry then, to venture an interpretation, is Woolf's own emphasis on the stream of consciousness, which she would perfect not in $M r s$ Brown but in Mrs Dalloway. Her style emphasies colliding, unconnected impressions; it uses long sentences separated by semicolons, which sometimes change their subject matter midway; it contains unexpected mixing of action and reminiscence of her characters; there is little description of social fact or of fixed psychological characteristics.

Let us, for now, then take this to be the relevant distinction. On one hand, we have the Edwardian style with creation of particular, contrasting personalities and attention to materialist detail; on the other, we have the Georgian style which does away with both of these features, and replaces them with a more meandering, stream of consciousness manner. Let us again emphasize that the relevant difference does not have to do with fictional content. It is not as if Arnold Bennett could not have written, within the confines of his style, that a character of his had a 'disjointed and meandering consciousness.' It is not that Virginia Woolf could not have included a few facts about the warts, buttons, ribbons and servants' wages in Mrs. Dalloway. The difference is in the manner and in the emphasis with which each writer would approach these elements of the fiction. This is precisely the suggestion that the example of Mrs. Brown seems to set up. Two writers of different camps could describe the same woman on the train; they could even 
include the same facts about her personality, situation and appearance, and would still arrive at different results in virtue of their different styles. ${ }^{16}$

With this difference in mind we can now turn to Woolf's other suggestion, which is that what each style represents differently is something about human nature. This could well strike one as a genuinely puzzling suggestion. How could a mere difference in style represent something different about human nature? Presumably, a view about human nature would have to be expressed with a general propositional statement. The two literary camps would have to put forward two mutually exclusive statements of the form 'It is a fact about human nature that...'; but a difference in style seems to have nothing do do with such statements. Further, the relevant difference is also not a difference in content. It is not the case that in Edwardian novels all characters exemplify one kind of human nature, and in Georgian novels they exemplify some other kind. It is not that humans are shown to have one kind of psychology in Edwardian novels, and a radically different one in Georgian novels; in fact, both camps can describe people in similar situations and with similar concerns. The relevant difference has to do with emphasis and structure, with how these characters are represented in a particular narrative style, not with what they are represented to be like. So how could this sort of difference represent something different about human nature?

Woolf's writings, I now want to suggest, not only pose this question but offer an interesting answer to it. The passage that most clearly articulates her view comes from a less well-known essay, David Copperfield. Here, Woolf is discussing Dickens rather than the Edwardians or the Georgians, but to the extent that she takes Dickens to be a formative influence on the Edwardians, the passage is very telling. It is worth quoting at some length: 
[W]hile we are under their spell, these great geniuses [writers of Dickens' stature] make us see the world any shape they choose. We remodel our psychological geography when we read Dickens; we forget that we have ever felt the delights of solitude or observed with wonder the intricate emotions of our friends, or luxuriated in beauty of nature. What we remember is the ardour, the excitement, the humour, the oddity of people's characters; the smell and savour and soot of London; the incredible coincidences which hook the most remote lives together; the city, the law courts; this man's nose, that man's limp; $[\ldots]$ And the fecundity and apparent irreflectiveness have a strange effect. They make creators of us, and not merely readers and spectators. ${ }^{17}$

Here Woolf seems to make a connection between literary achievement and the psychological effect literature has on the reader. She describes Dickens as someone who can 'remodel our psychological geography.' In describing this process as having to do with making 'creators of us' rather than merely 'readers and spectators', Woolf could be taken to point to the familiar effect of being able to look up from an absorbing work of literature, and see the world as modelled on it. When we read Dickens, for example, we can immediately make sense of our own environment in that peculiar Dickensian way: we can consider the people we know in terms of their pronounced physical and character traits; consider the places we are familiar with in terms of their excitement, oddities, and ardour. At the same time, certain other aspects of our lives fade into the background: we forget 'the intricate emotions of our friends'. An engrossing literary style, then, can be said to lead its reader to a certain set of cognitive habits, and hold her there. This is the 'spell' Woolf speaks of; the ability of writers to 'make us see the world any shape they choose.' 
If we were to connect this analysis of literary achievement to Woolf's discussion of differing representations of human nature, we might get clearer on why Woolf thinks a change in literary style in early $20^{\text {th }}$ Century marks such an important difference. Works of literature do not, for Woolf, represent different sets of general propositions or theories about human nature. Instead, a literary style represents a certain cognitive habit: a way of picking out certain features of personality as more salient than others, of privileging certain kinds of detail over others, of interpreting people's motivations and actions in some ways but not others. According to Woolf, the long realist tradition running from Dickens to Bennett privileged one such way of making sense of others - in terms of people's social status and pronounced character traits - and this exercised a tremendous influence over how the reading public made sense of their lives. ${ }^{18}$ To remodel that way of thinking, to upset that ossified 'psychological geography', the task of Woolf's own generation was to invent a new style of writing.

While there is some distance to be walked from an exegesis of Woolf's writings to a defensible philosophical position, I hope the case has been made that it would be worthwhile to go that distance. In the next section, I will return to that initial philosophical question - how can works of art represent something in virtue of their style? - and try and offer an answer in light of Woolf's remarks.

\section{A Woolfian theory of stylistic representation}

I have opened this discussion with the suggestion, taken from Danto, that works of art use the means of representation in a way that goes beyond the representation of their fictional contents. This use constitutes the artwork's style, and such style may 
by itself represent something in addition to the fictional contents. In relation to this thought, I now want to canvass two suggestions on the basis of Woolf's writings. The first is a suggestion about the form that philosophical argument about stylistic representation should take; the second contains a particular theory of stylistic representation.

First, let us try to give a more definite form to the suggestion that we think about literary style as a kind of representation. Woolf, as we saw, thinks of the difference in style as a difference in opinion: the strikingly innovative style of the Georgians - as seen, for example, in Woolf's own Mrs. Dalloway - is not just some strange new affectation; it has to do with the endeavour of the new generation to represent human nature in a new way. However, here arises a puzzle. On the one hand, Woolf's suggestion seems interpretatively plausible: it seems prima facie plausible to say that the style of Mrs. Dalloway represents human nature in a different way than the style of Edwardian literature represents it to be. The disjointed, fluid style of Mrs. Dalloway, as can be seen in the passage I quoted at the beginning of the paper, appears to suggest a human nature that is unstable and uncertain rather than determined by fixed character traits. On the other hand, however, the more we try to specify what it is exactly that the style of the novel represents about human nature, the more we need to exert ourselves interpretatively. What exactly is being represented? Is it a certain fact about human nature? Is it certain properties of the human psyche? Is it that these properties are predicated of a certain fictional person or of the human genus in general? And, given that the words 'human nature' are quite absent from the relevant passage of Mrs. Dalloway, how do we know that it is something about human nature that the style represents? None of this is quite clear. 
The puzzle then is that if we try to express in propositional form what a given style represents, we hit upon a certain indeterminacy. Perhaps this indeterminacy might be a good reason to drop the talk of representation altogether; it might lead us to dismiss Woolf's suggestion that different styles represent different views on human nature as pointing towards something hopelessly vague. For now, however, I want to see what happens if we take this indeterminacy instead to be something that an adequate theory of stylistic representation needs to explain.

Let me make this a bit clearer by comparing stylistic representation to other kinds of representation we study in aesthetics, such as pictorial depiction. Theories of pictorial depiction take it as their starting point that the pictorial content - that which is represented by a picture - is by and large determinate. Of course, there are ambiguous pictures like the duck-rabbit but most pictures are not like that. It is unproblematic that George Stubb's Whistlejacket represents a brown horse standing on its hind legs. What different theories of depiction tend to focus on primarily is not what pictures represent, but the relevant relation, which takes us from the pictorial surface to some determinate pictorial content. For example, some theories will claim Whistlejacket represents a horse because it resembles a horse in some restricted sense $;^{19}$ others that the picture represents a horse because it engages the perceptual mechanisms, which allow us to recognize horses. ${ }^{20}$ By contrast, the problem with stylistic representation occurs already a step earlier: the content, which the text stylistically represents, is itself an open question.

What seems to follow from this is that a theory of stylistic representation has a double task. First it needs to show what it is that a given style represents. A style, to reiterate, is a certain property of the text: a set of emphases, imagery, word choice, technique, and so on, which is recognizable across a given work. The chief puzzle 
for a theory of stylistic representation is that what some such a style represents seems only partially determinate. Only once a theory of stylistic representation has adequately captured what it is that a style can represent, can it proceed to specify what the relevant representational relation is; that is, what relation takes us from the literary text to the stylistically represented content. This framework is certainly experimental, and the tenability of it is yet to be demonstrated. What I want to do now is to formulate a theory of stylistic representation that fits this framework, and which I will derive from Woolf's writings on style.

The key suggestion I want to make on the basis of Woolf's essays is that a literary style represents a particular set of cognitive dispositions. As we saw, according to Woolf, the highly descriptive Edwardian style and the stream of consciousness Georgian style each represent human nature differently. However, they do not do so by means of a theory of human nature. A given style does not represent some set of propositions, but simply a way of thinking: what Woolf terms our 'psychological geography.' What the Edwardian and the Georgian style represent differently - to repeat - is a way of organizing information about people, a way of interpreting the reasons and causes behind their actions, a way of discriminating between important and unimportant facts about their personalities. Strictly speaking, then, it would be erroneous to say that a style represents some statement about human nature. Instead, a style represents a certain way of organizing information and making sense of people's natures. It represents a cognitive disposition that the reader may want to adopt.

Perhaps we can make this idea clearer by looking at other cases in philosophy where the distinction between propositional attitudes and cognitive dispositions has been made. One such case would be Gareth Evans' influential characterization of 
our tacit knowledge of the grammar of natural languages in terms of cognitive dispositions. ${ }^{21}$ What is curious about our knowledge of natural languages is that we seem to understand a potentially infinite number of sentences. To explain this fact, we can either - implausibly - attribute to speakers the knowledge of an infinite number of sentence-meanings; or we can - more plausibly - attribute to speakers the knowledge of compositional axioms of the language, which allow them to form and understand new sentences. Evans proposed that we think of such tacit knowledge as non-propositional. A competent speaker cannot be expected to articulate or even assent to the relevant axioms expressed as propositions. In addition, unlike with genuine beliefs, the speaker's knowledge of compositional axioms cannot be combined with other speaker's beliefs to yield further beliefs: our knowledge of compositional axioms does not appear to be at the disposal of our cognitive projects in the same way as our genuine propositional beliefs are. ${ }^{22}$ This lead Evans to conclude that our knowledge of these axioms is importantly subdoxastic. When we ascribe to a speaker the knowledge of a compositional axiom, we are simply ascribing to her a dispositional state: she is merely disposed to use language in a certain way. ${ }^{23}$ I will not here go into the details of Evans' argument. For our purposes it suffices that the contrast between tacit knowledge of compositional axioms and propositional attitudes is clear enough, and that the characterisation of the former in terms of cognitive dispositions, rather than in terms of propositional attitudes, is intuitively appealing. Then we may think of the contents that literary styles represent as similarly subdoxastic. A style represents a set of cognitive dispositions: a general modus operandi of gathering, organizing, and responding to information. 
The suggestion that a literary style represents a set of subdoxastic cognitive dispositions, rather than a set of propositions, I think, allows us to shine some light on the apparent indeterminacy of what it is that a literary style represents. Just as we may grasp new languages or dialects without propositionally grasping the axioms specifying their rules of composition, we may grasp the cognitive disposition of organizing information represented by Woolf's style, without being able to put our finger precisely on what axioms underlie that disposition. We can, of course, have a go at specifying such axioms with some level of accuracy. We might describe the disposition represented by Woolf's style as being governed by some axiom such as 'do not search for fixed character traits, but pay attention to people's associative thought processes', etc. Arguably this is the sort of project we engage with when we interpret what a given style is about. However, it is not the task of the literary writer to provide some such description of the cognitive dispositions she is representing by her style. Precisely what stylistic representation enables is to represent some such interesting new disposition without laying out the axioms. Similarly, the reader may recognize and be surprised or fascinated or attracted by the represented disposition without attempting to propositionally unlock the axioms that underlie it. We do not need to engage in some heavy-duty interpreting to be captivated by the way of making sense of others that Woolf's writing style represents.

Now we have some sense of what is being represented by a literary style: a set of cognitive dispositions. This, I propose, is how we should understand Woolf's suggestion that great literary authors shape our 'psychological geography.' An achievement of stylistic innovation has to do, at least in part, with succeeding in putting forward a representation of an intriguing new way of making sense of information. Accordingly, the achievement of Woolf's own modernist innovations 
in style can be appraised along these lines: it represents a way of making sense of others that privileges aspects of human nature previously overlooked.

As I argue in the next section, such a theory of stylistic representation could make for an exciting addition to the extant philosophical writings on literary style. However, it ought to be said that as a theory of stylistic representation, it is so far only part-complete. We now have an idea of what a literary style represents - a set of cognitive dispositions - but what remains to be established is how this happens. How do we get from reading a text with certain stylistic properties to a representation of a cognitive disposition? To illustrate by an analogy, a question that gets asked in theories of pictorial representation is: what relation takes us from the shapes on the pictorial surface to some depicted content? This relation is sometimes specified in terms of a necessary condition for a picture to depict some content: a picture $\mathrm{M}$ pictorially depicts some content $\mathrm{N}$ only if relation $\mathrm{R}$ obtains between $\mathrm{M}$ and N. Philosophers have offered different candidates for R: for example, $\mathrm{R}$ is sometimes theorised as some restricted resemblance relation between $\mathrm{M}$ and $\mathrm{N}$ (resemblance theories of depiction), or some relation that obtains between $\mathrm{M}$ and $\mathrm{N}$ in virtue of human perceptual mechanisms (recognitional theories of depiction). ${ }^{24}$ An analogous question for literary style would then be: what is the relation that obtains between a text written in a certain style and a set of cognitive dispositions?

I merely gesture at this issue as something that may be considered in the course of a further investigation. However, here too, I think, Woolf's writings may be of use. As said above, Woolf stresses the psychological effect that a literary style has on our way of thinking: writers 'make creators of us.' We can, after reading a few passages of Dickens, look away from the novel, and consider our academic 
colleagues as a comical and motley bunch with pronounced personal characteristics. We can, after a few pages of Woolf, consider them more sympathetically and plastically, less as fixed types. It might be that this effect is precisely the representational relation we are after. A given style $\mathrm{S}$, we might venture to say, represents a set of cognitive dispositions D only if S gets the reader to temporarily share D. This sort of thesis might command some plausibility in the light of the research on anchoring biases that is being done in cognitive psychology. As this work has shown, we are highly susceptible to adjusting our patterns of judgement depending on what kind of information we receive immediately prior to making a judgement. ${ }^{25}$ Literary style might work in a similar way: 'anchoring' our patterns of thought in a way that we can transfer to real life. A literary style represents a disposition that it habituates its readers to.

This is merely a further suggestion, though, which we need not accept in order to hold onto the more robust thesis that literary styles represent sets of cognitive dispositions. We may accept this thesis while leaving it open as to how exactly a literary style represents these dispositions. In the last section, I consider possible rivals to this view. As not much has been written specifically on the notion of stylistic representation, I look to related philosophical writings - on the cognitive value of art, definition of style, and expression - to construct a few possible alternatives.

\section{Some alternatives}

The first alternative might be to suggest that a work, in virtue of its style, does not represent a cognitive disposition but content in propositional form. We might get 
inspiration for this view from James Young's position on the cognitive value of art. Young argues that works of art engage in what he terms 'illustrative demonstration': by characteristically artistic means of exaggeration, comparison, and so on, works of art place the reader into a perspective from which some truth becomes apparent. ${ }^{26}$ One type of knowledge we gain in this way, according to Young, is propositional knowledge. For example, he suggests that Jane Austen's Emma puts the reader in a perspective from which it becomes apparent that 'it is dangerous to delight in making a sport of one's acquaintances'. ${ }^{27}$ Now, if we were to apply this view to style and apply it to the passage from Mrs. Dalloway, we could formulate a useful point of contrast to the view that a style represents cognitive dispositions. The passage, we could say, does not stylistically represent a cognitive disposition, but rather, by putting the reader into a particular perspective, illustratively demonstrates some general thesis. For example, we could say the passage puts the reader into a perspective from which a general proposition such as 'people's thought processes are meandering and unstable rather than fixed by stable character traits' becomes apparent.

I am not suggesting that Young would subscribe to such an interpretation of the passage from Mrs. Dalloway, since, as said, his theory concerns cognitive value of art as opposed to literary style as such. However, for the sake of drawing a contrast with the theory of stylistic representation outlined in the previous section, it seems important to note why it would be implausible to say that a literary style represents some propositional content. This suggestion seems to completely misrepresent the phenomenology of reading a stylistically distinct passage such as the one from Mrs. Dalloway. Nothing quite as distinct as some general thesis is formed before us while we read. Additionally, as I discussed above, if we do attempt to formulate 
some general thesis that the style represents, such statements often seem elusive and requiring interpretative strain. To suggest on the contrary that a writing style clearly represents some definite proposition seems to comically misrepresent the experience of reading. While reading, we do not exclaim, passage by passage: 'aha! I see what this is saying! People's thought processes are not fixed but meandering!' A remarkable style does not put before us some remarkable general statement, but a remarkable way of making sense of the word; that is, to put it in technical terms I have been employing, a remarkable cognitive disposition.

The second suggestion that I want to consider would be that a literary style does not represent some cognitive disposition, but rather expresses the author's personality, mental state or attitude. Here the important distinction is about who possesses the said disposition. My view is that a style represents a cognitive disposition simpliciter, whereas this alternative view would hold that the disposition - or indeed a personality, some mental state or attitude - is represented distinctly as belonging to the author. Perhaps the best place to look for such a view is Jenefer Robinson's proposal that literary style is an 'expression of [the author's] personality, or, more accurately, of the personality she seems to have. ${ }^{28}$ Just as the way of dress or the way of behaving at a party may be said to express a personality trait - where by saying that behaviour 'expresses' a personality trait we mean that it both exhibits and is caused by that trait ${ }^{29}$ - the real or implied author's literary style expresses her personality. ${ }^{30} \mathrm{We}$ could suggest, then, that what really goes on in the passage in Mrs. Dalloway is an expression of Woolf's particular personality, mental state or attitude towards life.

Robinson's suggestions do not arise out of an attempt to construct a theory of stylistic representation, but out of an attempt to conceptually define style, especially 
to establish what distinguishes an artist's individual style vis-à-vis a general style of an art historical movement. ${ }^{31} \mathrm{I}$ do not mean to comment on the aptitude of her proposal for settling that question. However, if we were to follow Robinson's view to suggest in addition that stylistic representation in works of literature represents an author's own psychological states, as opposed to some cognitive disposition simpliciter, I think this would yield rather implausible consequences. Virginia Woolf, as we saw, did not merely attempt to express some inner anxiety of hers, but attempted to open her readers' minds to how she felt human nature should be perceived, in general. Certainly, some writers might develop a particular style in order to showcase what they take to be an intriguing personality - either a character's or their own - perhaps in a similar way that other people express themselves through the style of their dress. However, I think this describes a special rather than the general case. Many if not most literary writers are concerned with developing ways of thinking about the world, which do not merely express a character trait, but which they take to be models for thinking that others too can benefit from. Woolf for one certainly saw herself as participating in the common intellectual project of making sense of our environment - a project that philosophers too participate in - and it would be unfortunate if we had to say that all she managed to express through her innovative style was her particular character traits.

The third view I should consider is one I suspect not many philosophers hold anymore, but that is so canonical it should at least be mentioned. This is Nelson Goodman's theory of expression as metaphorical exemplification. Danto considers Goodman's view specifically in connection to style, though he does not fully develop this thought: 
It might be possible to work our way concentrically outward from the concept of rhetoric, through the concept of expression, to the comprehensive concept of style, if Meyer Shapiro is right that style makes reference to "an overall quality which we may call 'expression,"' and if Nelson Goodman is right that expression is metaphorical exemplification. ${ }^{32}$

According to Goodman, what is expressed by a work of art W is a certain property $\mathrm{P}$ when $\mathrm{W}$ metaphorically exemplifies $\mathrm{P}$ : that is, when $\mathrm{W}$ metaphorically possesses $\mathrm{P}$, and also refers to $\mathrm{P}$ in virtue of that relation. ${ }^{33}$ By means of expression, works of art can represent properties they do not literally possess. For example, pictures can express feelings (sad, jubilant), properties of sound (melodious, dissonant) or of temperature (warm, cold). Along these lines, one could perhaps claim that literary styles also express such properties. ${ }^{34}$ Here are some suggestions. Perhaps we could say that Woolf's style expresses properties like meandering or disjointed.

Alternatively, we could say that the style expresses the properties that a meandering and disjointed thought process possesses. How would such views compare to the one I have been advocating?

It seems plausible to me to suggest that styles metaphorically possess certain features: that Woolf's style, for example, can be said to be disjointed or meandering. Other styles might be described as bleak, clinical, flowery, enthusiastic - all of which might be parsed as cases of metaphorical possession. However, I am not sure that it is helpful to suggest that a style also refers to these properties. First, it seems implausible to suggest that Woolf's style refers to the literal properties of being disjointed or meandering: properties that chains or rivers can have. While there might be some intuitive pull to saying that a (metaphorically) warm abstract painting refers to (literal) warmth, in a way that a tailor's swatch refers to a colour, I think there is no similar intuitive pull to saying that Woolf's style refers to some 
property a river or a chain might have. A flowery style similarly does not refer to flowers; a clinical style does not refer to clinics. Goodman's theory seems somewhat applicable to abstract painting or some music, but seems to be less so in the case of literary style.

To reiterate, I do not think that any of the philosophers I have here mentioned hold a theory of stylistic representation, and I do not think my arguments here necessarily apply against other theories they do hold, namely, theories about the definition of style, cognitive value or expression. I merely tried to use these philosophical writings to articulate some what may be felt to be genuine alternatives to my preferred view, and to lend plausibility to my view by showing their weaknesses.

\section{Style and aesthetic education}

To summarise, I have tried to show that stylistic representation is a type of representation. I argued for a thesis of literary stylistic representation based on the writings of Virginia Woolf: a literary style represents a set of cognitive dispositions. The cognitive dispositions that I discussed here had chiefly to do with how we make sense of other people's characters and thought processes, and the main example I used was that of Mrs. Dalloway. The next step for the theory would be to investigate to what extent it is applicable to other examples of literary style and other kinds of dispositions. Prima facie, however, there seems to be no obvious reason why the theory ought not to be generalizable in this way. If we are happy to grant that the modernist style of writing can open up new ways of thinking about people's characters, it should not be too difficult to show that other innovations in literary style can foster new cognitive dispositions for thinking about relationships, 
political institutions, religion, mortality, and indeed any topic that literature can address. The key point is that literary works do not represent propositions about these matters, but cognitive dispositions that have to do with how the reader actively perceives these matters: dispositions to privilege certain aspects of life over others, to pick out certain features as more salient than others, to reserve certain kinds of effective responses for those features.

By means of conclusion I want to say something about the broader interest of this thesis, specifically about the implication the thesis may have for the question of whether and how works of literature can yield knowledge. While an investigation into the representative capacities of literary style may well be of interest in and of itself, I now hope to suggest that such a theory can also motivate a more ambitious claim about the kinds of aesthetic education that literature makes available.

The position that literature is valuable because it yields knowledge is sometimes known as 'cognitivism', and can be summarised as making these two claims: (i) literature is in part valuable because it is a source of significant knowledge, and (ii) literature makes that knowledge available in virtue of features that constitute its identity as literature. ${ }^{35}$ The first claim explains the high regard we have for literature as an artform; literature, like philosophy or science, is a source of significant knowledge. 'Knowledge' here is usually broadly construed to include not just propositional knowledge, but other epistemically enhanced states like understanding, possession of a certain skill, and so on. The second claim needs to be met in order to ensure that the sort of knowledge made available by literature is made available non-accidentally, in virtue of specifically literary, artistic achievement. Uncontroversially, a work of literature can yield knowledge simply in virtue of any true descriptions it might contain, for example, about the historical 
times and places it describes. The sort of knowledge we are trying to capture needs to be tied more closely to specifically literary art, to something that sets literature apart from 'straightforward' history and reportage.

The goal of cognitivism, then, is to show that there is such a thing as a specifically literary, specifically aesthetic education. The theory of literary style I canvassed above, I now want to suggest, can supply the groundwork for making good such a claim. It is beyond my means here to put forward anything like a fullyfledged cognitivist theory; instead, I want to consider some steps which might get us there.

(1) First one would need to flesh out the sense in which a development of a stylistic representation constitutes a cognitive achievement, and the sense in which that achievement gets transferred to the reader. The first of these claims seems easy enough. Writing in a given a literary style is not merely a matter of choosing from an array of options; a style is something that an author hones and develops. Woolf writes eloquently on the difficulty of breaking with the preceding literary conventions; conventions, which have become so ossified as to seem natural; ${ }^{36}$ and so we might compare the cognitive achievement of creating a new style to the achievement of a philosopher who formulates a good alternative to a prevailing position. Importantly, however, one would also have to argue that this achievement gets transferred to the reader in the process of appreciating the new style - that there is a kind of learning that takes place through the reading. The crucial claim to make here is that the reader is not only able to recognize the cognitive disposition which a new style represents, but that she is able to acquire that disposition through the appreciation of the new style: that through reading she acquires an ability to see the world anew, as it were. 
I have suggested above that we might be able to understand the effects of literary style on our cognition as a kind of 'anchoring' of our cognitive biases. ${ }^{37}$ Psychologists have shown that random pieces of information can heavily influence our numerical and other estimations if they are relayed to us immediately prior to the guess. Perhaps works written in a distinct literary style, though describing fictional events irrelevant to our immediate environment, can similarly train us in obtaining specific thinking patterns, causing us to privilege certain kinds of information over other. (As a test, try reading a few paragraphs of Mrs Dalloway and then think of people you know). Perhaps the notion of cognitive anchoring may help us see how a kind of learning is taking place through literary style; a proper and thorough description of any such process, however, is still outstanding.

(2) If we could formulate a model of learning through style in a satisfactory way, how would it score against the two conditions imposed by cognitivism? The second condition - that literature must make knowledge available in virtue of features that are part of the literary art - would be easy enough to meet. A literary style is a characteristically literary trait, and so any knowledge made available through stylistic innovation would have to be put down to a specifically aesthetic education. To be able to fully subscribe to that claim, however, a difficult but essential step is missing. We would need to show that the cognitive achievement available through literary style leaves one epistemically better off. Perhaps works of literature do offer us new ways of organizing information and perceiving the world; but what makes any one of these a case of significant knowledge, rather than just an optional, non-veridical take on the information out there?

In order to decide on this question, one would have to make clear what kind of truth different stylistic representations are allegedly tracking. Should we say that 
either the Edwardians or the Georgians got it right, at the expense of the other party? Or can we tell a more complex story, suggesting that the truths of these different outlooks are complementary, or perhaps suggest that they are historically indexed? Once we make good the position that literary styles can educate our cognitive habits we are only halfway to a theory of aesthetic education; a more complete theory would require an exploration of the deeper epistemological and metaphysical commitments at play.

(3) Lastly, exploring the question of style would be fruitful in the context of the cognitivist theories about literature already on offer. Several models of literary knowledge have been developed in the past two decades or so; these include claims that literature yields practical moral knowledge, knowledge 'from-within' or 'what it is like', and education of emotions. For the most part, however, these models have been developed with regard to aspects of literary work other than the work's overall artistic style. Thus, for example, Martha Nussbaum has employed an Aristotelian framework to argue that a rich description of characters' moral reasoning enhances our moral understanding; ${ }^{38}$ Noël Carroll has written on how novels use contrasting literary characters to bring out finer distinctions of virtue and vice ${ }^{39}$ Berys Gaut has argued that works of literature can, much like good philosophical examples, enhance de se imaginings that yield knowledge of what it is like to be in a particular situation; ${ }^{40}$ and Jenefer Robinson has tried to show that engaging the reader in characters' fates can morally educate our emotions. ${ }^{41}$

At this point, I will leave it to the reader to consider whether there might be affinities between any of these views and the theory of stylistic representation I have been defending. My main aim so far has been to canvass the possibility that literary style is another means of representation - albeit a means of representing 
cognitive dispositions rather than a means of representing facts. If my derivations from Woolf are at all convincing, such a view is not entirely without precedent. And while a theory of stylistic representation is not the whole story as far as a full cognitivist thesis is concerned, it might be a good first step. ${ }^{42}$ 


\section{Notes}

1. Virginia Woolf, Mrs. Dalloway (Penguin: London, 1964): 5.

2. Arthur Danto, The transfiguration of the commonplace (Cambridge, Mass: Harvard University Press, 1981): 148.

3. Ibid.: 198.

4. Richard Wollheim, 'Pictorial Style: Two Views', in The Mind and Its Depths (Cambridge, Mass.: Harvard University Press, 1993 [1979]); J. M. Robinson, 'Style and significance in art history and art criticism', Journal of Aesthetics and Art

Criticism 40: 1 (1981); Arthur Danto, 'Narrative and Style', JAAC 49: 3 (1991), J.

D. Carney, 'Individual Style', JAAC 49: 1 (1991).

5. E.g. Danto, Transfiguration, pp. 146-9; 165ff.; Robinson, 'Style and significance in art history and art criticism', pp. 144-149.

6. E.g. Dominic Lopes, 'Pictorial realism', JAAC, 53: 3 (1995). John Hyman,

The objective eye: color, form, and reality in the theory of art, (Chicago: University of Chicago Press, 2006), pp. 181-210. Catharine Abell, 'Pictorial realism', Australasian Journal of Philosophy, 85: 1 (2007).

7. Virginia Woolf, 'Modern Fiction', in Collected Essays, Vol. 2 (London:

Hogarth, 1967 [1917]); Virginia Woolf, 'Mr. Bennett and Mrs. Brown', in Collected Essays, Vol. 1 (London: Hogarth, 1966 [1923]); see also her reviews of Bennett and Galsworthy in Virginia Woolf, Contemporary Writers (New York: Harcourt, Brace Jovanovich, Inc., 1965).

8. Woolf, 'Mr. Bennett and Mrs. Brown': 320.

9. Ibid.: 330.

10. Ibid.: $330 \mathrm{ff}$.

11. Ibid.: 325.

12. Ibid.: 319.

13. Woolf, 'Mr. Bennett and Mrs. Brown': 332.

14. Woolf, 'Modern Fiction': 104.

15. Woolf, 'Mr. Bennett and Mrs. Brown': 336.

16. Raymond Queneau's postmodernist classic Exercises de Style (Gallimard:

Paris, 1947) rewrites the same fictional contents in no less than 99 different styles.

17. Virginia Woolf, 'David Copperfield', in The Moment and other essays (San Diego: Harcourt Brace \& Company, 1975 [1947]): 78.

18. Woolf, 'Mr. Bennett and Mrs. Brown', pp. 333,336.

19. Hyman, The objective eye.

20. Dominic Lopes, Sight and sensibility : evaluating pictures (Oxford: Oxford University Press, 2005).

21. Gareth Evans, 'Semantic Theory and Tacit Knowledge', in Collected Papers, (Oxford: Oxford University Press, 1985).

22. Ibid.: 133.

23. Cp. ibid., pp. 124-125. 
24. Cp. Catharine Abell and Katerina Bantinaki, 'Introduction' in Abell and Bantinaki, eds., Philosophical Perspectives on Depiction (Oxford: Oxford University Press, 2013), pp. 2-6.

25. Daniel Kahneman, Thinking, fast and slow (London: Penguin, 2011), pp. 119-128. I am grateful to Gail Leckie for pointing me in the direction of Evans' work on tacit knowledge and Kahneman's work on anchoring.

26. James O. Young, Art and Knowledge, (London: Routledge, 2001): 69.

27. Ibid.: 95 .

28. J. M. Robinson, 'Style and personality in the literary work', The

Philosophical Review, vol. 94, no. 2 (1985): 227. Robinson's position is inspired by Richard Wollheim's analysis of style in visual art; see his 'Pictorial Style: Two Views.' Incidentally, Wollheim's discussion of a painter's 'psychomotor dispositions' (pp. 176-7) that make up her style resonates with my preferred view, though Wollheim's attention here is specifically on visual arts in a way that is not obviously transferrable to literature.

29. Robinson, 'Style and personality in the literary work': 229.

30. Ibid.: 231 .

31. Ibid.: 227.

32. Danto, Transfiguration: 189.

33. Nelson Goodman, Languages of art: an approach to a theory of symbols, (Indianapolis: Hackett Pub. Co, 1976): 95. See also pp. 85-95.

34. Jenefer Robinson has also argued for a Goodmanian view that works of art can express complex properties and express them about the world. J. M. Robinson, 'Expressing the Way the World Is: Expression as Reference', Journal of Aesthetic Education 13: 1 (1979).

35. Cp. Cynthia Freeland, 'Art and Moral Knowledge', Philosophical Topics 25 (1997): 19. Matthew Kieran, 'Value of Art', in Berys Gaut and Dominic Lopes (eds.) The Routledge Companion to Aesthetics, 2nd ed. (London: Routledge, 2005): 299. Berys Gaut, 'Art and Cognition', in Matthew Kieran (ed.) Contemporary Debates in Aesthetics and the Philosophy of Art, (Oxford: Blackwell, 2006): 115. 36. Woolf, 'Mr. Bennett and Mrs. Brown': 336.

37. See note 25 above.

38. Martha Nussbaum, Love's knowledge, (Oxford: Oxford University Press, 1990): 148-67.

39. Noël Carroll, 'The Wheel of Virtue: Art, Literature, and Moral Knowledge', Journal of Aesthetics and Art Criticism 60: 1 (2002).

40. Berys Gaut, Art, Emotion and Ethics, (Oxford: Oxford University Press, 2007): $157 \mathrm{ff}, 186 \mathrm{ff}$.

41. Jenefer Robinson, 'L'Education Sentimentale', Australasian Journal of Philosophy 73: 2 (1995).

42. This paper began life as my B.Phil. thesis at Oxford University, where it has benefitted enormously from discussions with my supervisor Edward Harcourt. It has undergone several transformations since then, and many conversations have helped it along the way. I am grateful to Peter Dennis, Louise Hanson, Andrew Huddleston, Gail Leckie, Asya Passinsky, John Searle and Helen Sims-Williams for their time and commentary. 